\title{
Proceedings of the meeting of the Society of British Neurological Surgeons
}

\author{
The 115th Meeting was held in Newcastle upon Tyne, 20-22 September 1989
}

PROBLEMS IN THE MANAGEMENT OF POSTERIOR CIRCULATION ANEURYSMS

RP Sengupta. Newcastle

Direct obliteration of aneurysms in the posterior circulation is much more difficult than those in the anterior circulation. Very few surgeons have been able to achieve surgical results as good as those of Drake or Yasargil. Although the author had obtained good results in anterior circulation aneurysms, the outcome in posterior circulation aneurysms was far from satisfactory. From painful experience with a small series the author had learned that the difficulty of successful outcome in these aneurysms was mainly a reflection of a lack of experience with these rather rare aneurysms, difficulty of exposure, manipulation of the vessels of the brainstem and difficulty of proximal control.

\section{MANAGEMENT OF INTRACEREBRAL}

HAEMATOMAS: AUDIT OF CLINICAL PRACTICE 1988

PF Statham, NV Todd. Glasgow

The clinical management of all patients admitted with a diagnosis on computed tomography (CT) of intracerebral haematoma during 1988 was audited to establish if aetiology was important for management and outcome. One hundred and eighty four patients with a supratentorial haematoma of

Table Clinical and radiological features:

\begin{tabular}{|c|c|c|c|c|}
\hline & $A g e^{\star}(y r s)$ & $\begin{array}{l}\text { Time to } \\
\text { admission * (hrs) }\end{array}$ & $G C S^{\star}$ & $\begin{array}{l}\text { Focal } \\
\text { deficit } \%\end{array}$ \\
\hline $\begin{array}{l}\text { Trauma } \\
\text { Spontaneous } \\
\text { "Aneurysmal" }\end{array}$ & $\begin{array}{l}54 \\
53 \\
54\end{array}$ & $\begin{array}{l}12-24 \\
12-24 \\
12-24\end{array}$ & $\begin{array}{l}12 \\
12 \\
13\end{array}$ & $\begin{array}{l}50 \\
80 \\
59\end{array}$ \\
\hline
\end{tabular}

\begin{tabular}{llll}
\hline & Haematoma volume $(\mathrm{mls})$ & Cistern effacement \% & Clinical deterioration \% \\
\hline Trauma & 14 & 35 & 42 \\
Spontaneous & 27 & 66 & 41 \\
"Aneurysmal" & 15 & 42 & $55 \star_{\text {median }}$ \\
\hline
\end{tabular}

Surgical management:

\begin{tabular}{lllllllll}
\hline & \multicolumn{3}{l}{ Haematoma } & not evacuated & & \multicolumn{3}{l}{ Haematoma evacuated } \\
\cline { 2 - 4 } \cline { 7 - 9 } & Stable & Deterioration & Total & & & Stable & Deterioration & Total \\
\hline Trauma & 32 & 14 & 46 & & 8 & 12 & 20 \\
Spontaneous & 28 & 19 & 47 & & 7 & 4 & 11 \\
"Aneurysmal" & 29 & 27 & 56 & & & 1 & 1 \\
\hline
\end{tabular}

Outcome: (assessed by Glasgow Outcome Scale).

\begin{tabular}{|c|c|c|c|c|c|c|}
\hline & \multicolumn{3}{|c|}{ Stable } & \multicolumn{3}{|c|}{ Clinical deterioration } \\
\hline & $D / V$ & $S D$ & $M / G$ & $D / V$ & $S D$ & $M / G$ \\
\hline $\begin{array}{l}\text { Trauma } \\
\text { Spontaneous } \\
\text { "Aneurysmal" }\end{array}$ & $\begin{array}{l}0 \\
1 \\
0\end{array}$ & $\begin{array}{r}6 \\
10 \\
3\end{array}$ & $\begin{array}{l}32 \\
23 \\
22\end{array}$ & $\begin{array}{r}8 \\
13 \\
23\end{array}$ & $\begin{array}{l}7 \\
2 \\
3\end{array}$ & $\begin{array}{r}13 \\
9 \\
5\end{array}$ \\
\hline
\end{tabular}

Traumatic intracerebral haematomas ( $\mathrm{TICH}$ ) are diagnosed now more often in life with the widespread availability of CT scanning. Their clinical course is unpredictable, and the role of surgical evacuation in management is controversial. Data from the clinical and radiological records of 202 patients (151 male, 51 female) with TICH admitted to neurosurgical units in Britain were subjected to multivariate analysis.

One hundred and two patients were classed as good (Glasgow Outcome Scale 1-2) and 100 as bad (GOS 3-5). The Glasgow Coma Score (GCS) was a major determinant of outcome; a score on admission of 12 or greater gave a probability of 3:1 of a good outcome. This fell to $1: 3$ for a score of seven or less. Multiple haematomas, large size and central location each carried a poor prognosisirrespective of the GCS on admission. The best results following surgery were obtained in patients with a GCS greater than 12 when their haematoma was removed before deterioration. In patients who deteriorated, those who had surgery fared better than those who did not. Age and nature of trauma had no significant effect on outcome.

\section{FAMILIAL SUBARACHNOID HAEMORRHAGE} IC Bailey. Belfast

Over the past 15 years the incidence of subarachnoid haemorrhage occurring in more than one member of the same family had been investigated. Thirteen families had been recognised in whom two or more members had had proven subarachnoid haemorrhage. In a further 17 instances a family history of subarachnoid haemorrhage was strongly suspected but not definitely proven because of the lack of confirmatory evidence by angiography, CT scan or autopsy.

Certain features of subarachnoid haemorrhage in these families was noted. Sibling subarachnoid haemorrhage often occurred at the same age and this was younger than the mean age of haemorrhage in the general population. The distribution of aneurysms was often identical and multiple aneurysms occurred more commonly than expected. If more than two members of a family had aneurysmal subarachnoid haemorrhage, there was an increased risk of other members of the family having asymptomatic aneurysms. Prophylactic scanning or angiography is recommended in such cases. These findings suggest that there is a genetic factor in the causation of subarachnoid haemorrhage in some instances.

EARLY SURGERY FOR RUPTURED ANEURYSMS: SHOULD WE CONTINUE? AD Mendelow, RP Sengupta, P Geeta. Newcastle

While it is desirable to report management mortality for subarachnoid haemorrhage based on a complete Regional population rather than operative mortality, this is often impossible in units in the United Kingdom because of different referral patterns and inter-consultant referrals. However, most 
surgeons are able to audit their own operative results, and this study reports the operative results with early surgery of two neurosurgeons who have tended to operate as soon after the ictus as possible. Two hundred and five patients had definitive aneurysm surgery within four days of their haemorrhage, while 696 were operated upon after five days. Overall, there was no difference in the outcome between the two groups (table 1).

Table 1 Outcome

\begin{tabular}{lrr}
\hline & Early & Late \\
\hline Good recovery & $71 \%$ & $73 \%$ \\
Moderate disability & $19 \%$ & $17 \%$ \\
Severe disability & $1 \%$ & $4 \%$ \\
Vegetative & $0 \%$ & $0 \%$ \\
Death & $8 \%$ & $6 \%$ \\
Unknown & $1 \%$ & $0 \%$ \\
\hline
\end{tabular}

Table 2 Mortality for each grade

\begin{tabular}{lrr}
\hline & Early & \multicolumn{1}{c}{ Late } \\
\hline Grade I & $4 \%$ & $3 \%$ \\
Grade II & $7 \%$ & $6 \%$ \\
Grade III & $11 \%$ & $6 \%$ \\
Grade IV & $60 \%$ & $21 \%$ \\
Grade V & $50 \%$ & $100 \%$ \\
Unknown & $0 \%$ & $13 \%$ \\
\hline
\end{tabular}

Each of the two Neurosurgeons had a learning curve with early surgery: the mortality fell from $13 \%$ initially to $4 \%$ more recently. With late surgery no such learning curve was seen. The mortality was much higher in Grade III and Grade IV patients, both with early and late surgery. These results suggest that early surgery can be practised safely in selected patients (Grade I and Grade II)-delaying surgery in these patients therefore exposes them unnecessarily to risk of further haemorrhage.

\section{WHAT IS OPTIMAL MANAGEMENT FOR}

PATIENTS OVER 60 YEARS WITH

SUPRATENTORIAL GLIOMA? LESSONS FROM AN AUDIT

S Denholm, K El Shunnar, IR Whittle. Edinburgh

The place of multidisciplinary intervention in elderly patients with gliomas is a controversial question. The proportion of elderly people in the UK is increasing. There is growing pressure for cost-effective medical management yet the natural history of gliomas in this group is poor, and all treatment modalities are potentially hazardous. To address the questions of management and outcome an audit of patients aged over 60 years with gliomas treated at the Department of Clinical Neurosciences between 1982-89 was undertaken.

Eighty patients were reviewed. Surgical procedures included biopsy by craniotomy, burrhole or BRW stereotaxis, and tumour debulking using either formal or stereotaxic microsurgical craniotomy. Tissue diagnoses were Gr III-IV glioma (63), Gr II glioma (5) with 12 patients having a CT diagnosis of malignant glioma. Treatment, median survival times (ST) and median length of hospital stay (not including radiotherapy) were:
There was no consistent relationship between treatment and either location of the tumour or WHO functional status at presentation. Patients with good WHO grade survived longer than those in poorer grades (1-32 weeks; 2-20 weeks; 3-14 weeks; 4-9 weeks). There was considerable morbidity $(30 \%)$ and mortality (12\% at 30 days) after craniotomy.

This study has shown that there is no consistent approach to the management of elderly patients with gliomas in our unit. Management does not greatly influence survival time. Although cytoreductive surgery and radiotherapy offer a modest survival advantage there is also an increased morbidity and longer hospitalisation. Management protocols that assess quality of life provided by treatment as well as survival time are clearly required in these patients.

EFFECT OF DEBULKING SURGERY ON SURVIVAL IN MALIGNANT ASTROCYTOMA

S Falci, DL Silbergeld, BA Bell. Atkinson Morley's, London

Long term survival in patients with malignant astrocytomas has changed little over the past two decades. Surgery to debulk the tumour is widely practised, although it has not been shown to have a large effect per se on long term survival. Radiotherapy combined with partial tumour excision has been shown to prolong survival, with little additional benefit from chemotherapy. CT guided stereotaxy has made biopsy of even smal deep tumours relatively safe, and it is possible that stereotaxic biopsy and radiotherapy could be just as effective as more extensive surgery and radiotherapy.

Seventy three patients were reviewed with Kernohan Grade III or Grade IV astrocytomas in whom stereotaxic biopsy was their only surgical procedure. When compared to historical controls who underwent partial tumour excision, with or without radiotherapy, ${ }^{1}$ no difference in survival was found between debulking surgery alone versus stereotaxic biopsy alone, nor between debulking followed by radiotherapy and stereotaxic biopsy followed by radiotherapy. The median survivals for debulking surgery alone and stereotaxic biopsy alone were four months and two months respectively, and for debulking followed by radiotherapy and tereotaxic biopsy followed by radiotherapy, 9.3 months and eight months respectively.

Stereotaxic biopsy with radiotherapy does therefore seem to be just as effective as more extensive surgery with radiotherapy, and with such a low morbidity and mortality attached to stereotaxic biopsy, ${ }^{2}$ more extensive surgery for Grade III and Grade IV gliomas may be avoided. If stereotaxic biopsy reveals a lower grade tumour, debulking may be worthwhile and may improve survival.

1 Salcman M. Neurosurgery 1980;7:435-40. MacKenzie AI, Bell BA, Marsh HT, Uttley D. J Neurol Neurosurg Psychiatry 1990 (in press).
ANTIBODY TARGETED IRRADIATION FOR

LEPTOMENINGEAL NEOPLASIA: CURRENT STATUS

RP Moseley, JC Benjamin, HB Coakham. Bristol. JT Kemstead, LS Lashford. London

Neoplastic meningitis is a devastating complication of malignant disease and is usually associated with survival of less than three months.' A series of 18 clinically evaluable patients had been treated in the Bristol United Hospitals by a single administration of intrathecal monoclonal antibody labelled with 30-60 $\mathrm{mCi}^{131} \mathrm{I}$. (Medulloblastoma 3, ependymoma 1 , teratoma 1 , pineal tumour 2 , glioma 1, B-lymphoma 1, melanoma 3, carcinoma 6.) All patients were in relapse and did not receive adjuvant irradiation to evaluable disease within six weeks of immunoconjugate administration.

Immunoscintigraphy revealed accumulation of immunoconjugate at neuraxial sites corresponding with clinically suspected or radiologically demonstrated disease. Results were documented in terms of (1) removal of tumour cells from CSF, (2) neurological improvement and (3) survival. CSF responses were seen in $8 / 16$ cases $(50 \%)$, neurological responses in $7 / 18(38.9 \%)$. Survival ranged from $1-44$ months. Long term survivors remained in complete remission at 22 and 27 months after therapy. Manifestations of acute toxicity included meningism, bone marrow suppression and seizures. No chronic toxicity had been observed in the longest survivors. These initial results are being evaluated in ongoing clinical trials.

1 Giannone L, Greco FA, Hainsworth JD. J Clin Oncol 1986;4:68-73.

THE GROWTH RATE OF HUMAN PITUITARY TUMOURS. A FLOW CYTOMETIC STUDY USING IN-VIVO BROMODEOXYURIDINE

PL May, G Forster, D Spiller, T Cooke, RV Jeffreys. Liverpool

Although most pituitary tumours are regarded as benign, there is a significant rate of local recurrence and a few are frankly malignant. The prediction of clinically aggressive behaviour by histopathological means is inadequate and the selection of patients for post-operative radiotherapy is often empirical. The flow cytometric analysis of the DNA content of certain intracranial tumours has suggested that a high proliferative index may relate to a tendency to recur.

The in-vivo administration of bromodeoxyuridine (BUDR) yields a reliable and accurate S-phase labelling index and evaluation by flow cytometry allows a much greater and therefore more representative number of cells to be examined. Previous authors have described the immunohistochemically derived S-phase fraction of pituitary tumours following the in-vivo administration of BUDR $^{\prime}$ and have suggested a correlation between values of greater than $1 \%$ and aggressive behaviour. Others have used the monoclonal antibody $\mathrm{Ki}-67$ to assess the growth fractions of pituitary adenomas and have shown that invasive tumours had a significantly higher value than non-invasive tumours. $^{2}$

The authors reported their initial experience with the flow cytometric evaluation of the S-phase fraction in a group of pituitary tumours following the pre-operative administration of BUDR and discussed the correlation between high values of S-phase fraction and clinically aggressive behaviour. 
1 Nagashima T, Murovic JA, Hoshino T, et al. J Neurosurg 1986;64:588-93.

2 Landolt AM, Shibata T, Kleihues P. J Neurosurg 1987;67:803-6.

MEASUREMENT OF CRANIOSPINAL

COMPLIANCE: AN IMPROVED METHOD

IR Piper, JD Miller, IR Whittle, A Lawson. Edinburgh

In an effort to find a more exact and less invasive way of measuring craniospinal compliance, traditionally calculated from the pressure response following a bolus injection into the CSF space (VPR), we have developed an automated method that uses an electronic square wave pulse generator to produce a small $(0.05 \mathrm{ml})$, exact and reproducible transient volume increase in the CSF space (pulse duration $=100 \mathrm{msec}$ ). The amplitude of the ICP response (Pulse response) to this volume increment is time-averaged using a biological signal averager.

In an experimental model of intracranial hypertension in cats $(n=4), I C P$ was raised, through intraventricular infusion of mock $\mathrm{CSF}$, in increments from $10 \mathrm{~mm} \mathrm{Hg}$ to 110 $\mathrm{mm} \mathrm{Hg}$. At each level of ICP, compliance was measured sequentially both by the VPR method and the new pulse response method. The VPR method always overestimated compliance compared to the pulse method ( $p<$ $0.001)$. The pulse response method showed less variance with a coefficient of variation (CV) ranging from $1 \cdot 2 \%$ to $4.2 \%$ (mean CV $=2.6 \%$ ) compared to a $\mathrm{CV}$ ranging from $3.2 \%$ to $21 \%$ (mean $\mathrm{CV}=7.6 \%$ ) with the VPR method.

This new technique appears to be a more sensitive and exact way of measuring intracranial compliance which offers the potential for more accurate monitoring of deleterious changes in intracranial dynamics that could possibly lead to earlier or more effective management of conditions complicated by increased ICP.

\section{NEW LAMPS FOR OLD}

GA Flint. Birmingham

Stereotactically guided biopsy of small or deep seated lesions of the brain has now become a standard neurosurgical technique, facilitated by computerised tomographic localisation of the target areas. The better known and commercially available stereotactic frames have been modified so that they can be readily interfaced with scanning equipment. The cost of equipping a department with such apparatus is quite considerable and financial considerations may discourage a unit from developing this form of surgery. Alternatively, units may possess stereotactic equipment, designed originally for ablative procedures, which is not available commercially but which could be modified for use with a CT scanner with relative ease and at little expense. The author described how the Hughes stereotactic apparatus had been modified and developed for this purpose.

\section{STAB INJURY TO THE HEAD AND SPINE} N Rawlinson. Bristol

Nine cases of stab injury were presented who had been managed in the Department of Neurosurgery, Groote Schuur Hospital, Cape Town.

The incidence of stab injury is increasing in the non-white community. The majority are alcohol related. Injury to the brain or spinal cord may occur as part of a frenzied attack with multiple stab wounds, or as a premeditated single injury. Six of these injuries occurred to the head and three to the spine.

In the skull this type of penetrating injury is characterised by a trivial entry wound and deceptively mild clinical presentation. However, there is delayed morbidity and mortality from infective or vascular complications. In the spine the paraplegia may prove lethal. In the skull these injuries are managed by aggressive investigation and surgery (CT scan and angiography). Surgery is indicated for frontal sinus injury and dural tear, abscess, haematoma or vascular complication. Conversely, in the spine, the management of a stab injury is conservative, the emphasis being on rehabilitation.

\section{OSSIFICATION OF CERVICAL POSTERIOR}

LONGITUDINAL LIGAMENT

TKY Lee, PB Chacha, J Khoo. Singapore

Personal experience of six cases of the posterior longitudinal ligament (OPLL) of the cervical spine, four of which required surgery, prompted review of all the cervical spine radiographs in the authors' hospital Out of 5,167 reports, 37 cases of OPLL were found forming the largest study of this disease outside Japan. OPLL was thought previously to be unique to the Japanese. The incidence of $0.75 \%$ was similar to that found in Japan but the disease seemed milder in Singapore. The male to female ratio was 3:1 and associations between OPLL, diabetes mellitus and ankylosing spondylitis were discovered Twelve patients had associated calcification of other cervical ligaments, particularly the anterior longitudinal spinal ligament. Hence a tendency to calcification may be important in the aetiology of OPLL. In this series anterior spinal fusion with removal of the ossified ligament or multi-level laminoplasty gave satisfactory results.

THE VALUE OF MRI IN THE FOLLOW UP OF SPINAL INJURIES

P Sett, HA Crockard. Queen Square, London

In the follow up management of spinal injuries it is important to determine the extent of the cord injury and to detect the development of secondary complications such as syrinx and compression due to skeletal deformity. History and clinical examination may not necessarily alert the clinician until a late stage. Nineteen patients (12 males, seven females; age 19-44 years) with cord injuries had had an MR scan. Injuring mechanism included RTA, falls, epilepsy, bomb blast and penetrating injuries.

The MR scan revealed the extent of injury: two patients had transections and two had contusions of cord allowing definitive prognosis. Persisting cord compression was seen in five patients (four cervical, one thoracolumbar); all had surgery, with improvement in three. Syrinx and cord cysts were seen in six; three had surgery on more than one occasion, one had a single operation and in two the cysts did not expand and did not require surgery. Unsuspected pathology was noted in four patients-angiolipoma, hydromyelia, odontoid fracture and extradural meningocele.

The authors recommended that MRI should be a base line follow up investigation for all spinal cord injuries.
PRESSURE GRADIENTS IN IDIOPATHIC SYRINGOMYELIA-MANAGEMENT IMPLICATIONS

MD du Trevou, MR Bullock, JR von Dellen. Glasgow

In 15 patients with idiopathic syringomyelia pressures were simultaneously measured under various physiological conditions in the syrinx, spinal subarachnoid space and cisterna magna. At rest the pressures were equal and fluctuated with respiration but when the intra abdominal pressure, measured with a rectal catheter, was increased pressure differentials developed. Three types of syringomyelia were identified, each with its own management implications.

\begin{tabular}{|c|c|c|}
\hline & \multicolumn{2}{|l|}{ Communication } \\
\hline & $\begin{array}{l}\text { Spinal/cranial } \\
\text { subarachnoid } \\
\text { spaces }\end{array}$ & $\begin{array}{l}\text { Cranial } \\
\text { subarachnoid } \\
\text { space/syrinx }\end{array}$ \\
\hline $\begin{aligned} \text { I } \\
\text { II }\end{aligned}$ & $\begin{array}{l}\text { Obstructed } \\
\text { Obstructed } \\
\text { Communicating }\end{array}$ & $\begin{array}{l}\text { No communication } \\
\text { Communicating } \\
\text { Communicating }\end{array}$ \\
\hline
\end{tabular}

There were five patients in each category. Type I had two subgroups. In type IA the syrinx pressure was higher than in the spinal subarachnoid space and in type IB they were equal.

The authors suggested that patients with idiopathic syringomyelia are a diverse group and if the aim of the surgery is to normalise fluid dynamics then one-third of patients (type III) may not be surgical candidates. Types I and II require a procedure to relieve the obstruction between the cranial and spinal subarachnoid. In addition, type IA would respond to a syringo-subarachnoid shunt and type II to a syringo-peritoneal shunt. The patients continue to be followed up clinically, radiologically, and with repeat pressure measurements.

IDIOPATHIC COMMON PERONEAL NERVE PALSY TJD Pigott, D Jefferson, DT Hope. Nottingham

Sixty six patients with foot drop presenting over an eight year period were retrospectively analysed. Previous studies ${ }^{12}$ had tended to concentrate on those cases of known aetiology. There were 13 idiopathic cases. The mode of onset was relatively acute, with an age range of 16 to 80 years (mean 49 years). Ten patients had partial lesions; the remaining three had complete lesions with no evidence of nerve function on nerve conduction velocity.

Of the patients with incomplete lesions, eight had begun to recover within three months, one within 12 months and one within 14 months. Two of the three with complete lesions had surgery with no benefit at nine months.

In conclusion, incomplete idiopathic common peroneal nerve palsy can be expected to recover without intervention, but a complete lesion probably will not. Surgery is of doubtful benefit.

1 Berry H, Richardson PM. J Neurol Neurosurgery Psychiatry 1976;39:1162-71.

2 Katirii MB, Wilbourn AJ. Neurology 1988;38: 1723-8. 
ADMISSION AND TRANSFER OF HEAD INJURIES The Round Table Discussion was based on three short papers:

1 COMMUNICATION FAILURE IN HEAD INJURY MANAGEMENT.

G Quaghebeur, P Richards. Charing Cross, London

In 1984 a set of guidelines for the initial management of head injuries were published by a group of Neurosurgeons in the British Medical Journal. ${ }^{1}$ Despite the clarity of these guidelines inappropriate management and referral of head injuries still occurs in many Accident and Emergency Departments. In particular there seems to be a general failure to urgently refer patients with a reduced level of consciousness and a skull fracture.

A questionnaire was sent out to Orthopaedic and Surgical Registrars engaged in primary head injury management in two regions. The results indicated widespread ignorance of the existence of these guidelines, let alone knowledge of their contents. A review of popular undergraduate and postgraduate text books on surgery was undertaken and their advice on head injury management noted. Again the guidelines were rarely mentioned, particularly undergraduate text books. In some books the advice offered would now be considered woefully outdated. It appears that the message on how to manage head injuries is not reaching those primarily involved in their care with the result that some patients are receiving inappropriate management.

\section{Briggs M, Clarke P, Crockard HA, et al. Br Med J} 1984;288:983-5.

2 PULSE OXIMETRY DURING INTER-HOSPITAL TRANSFER OF HEAD-INIURED PATIENTS D Gentleman, R Patey. Glasgow

Pulse oximetry had been used to monitor the oxygenation of 25 head injured patients before and during ambulance transfer to a regional neurosurgical unit, using a Novametrix 505 pulse oximeter which both displays data and stores it for printing. All but two patients had an altered conscious level, nine $(36 \%)$ were in a coma, four $(16 \%)$ were multiply injured, and six $(24 \%)$ underwen intracranial surgery after transfer. Technically satisfactory recordings of oxygen saturation lasting for 30-98 minutes were obtained in 23 patients $(92 \%)$, six $(27 \%)$ of whom had episodes of oxygen desaturation. The recordings were unsatisfactory in the other two patients because of extreme restlessness and repeated disconnection of the probe. No patient deteriorated neurologically en route and none arrived hypoxic at the neurosurgical unit.

It proved feasible and straightforward to monitor arterial oxygen saturation continuously during the resuscitation and transfer of acutely head injured patients. Further studies with more patients are needed to assess whether this will affect the frequency or severity of early hypoxia after head injury.

3 EXTRADURAL HAEMATOMA IN THE IRISH REPUBLIC - AN ANALYSIS OF 88 CASES WITH EMPHASIS ON DELAY

MGJ O'Sullivan, W Gray, TF Buckley. Cork

Delayed surgery adversely affects the out-

\begin{tabular}{|c|c|c|c|c|c|c|c|}
\hline \multirow[b]{2}{*}{ Source of referral } & \multicolumn{4}{|c|}{$\begin{array}{l}\text { Glasgow Coma Score on } \\
\text { arrival }\end{array}$} & \multicolumn{3}{|c|}{$\begin{array}{l}\text { Duration of } \\
\text { transfer (hours) }\end{array}$} \\
\hline & No & $(3-4)$ & $(5-8)$ & (8) & $(0-3)$ & $(3-5)$ & (5) \\
\hline $\begin{array}{l}\text { In hospital } \\
\text { Inter hospital } \\
\text { Direct }\end{array}$ & $\begin{array}{l}11 \\
23 \\
12\end{array}$ & $\begin{array}{l}3 \\
6 \\
3\end{array}$ & $\begin{array}{l}4 \\
7 \\
4\end{array}$ & $\begin{array}{r}4 \\
10 \\
5\end{array}$ & $\begin{array}{l}5 \\
7 \\
\text { (Time } \\
\text { case }\end{array}$ & $\begin{array}{l}5 \\
3 \\
\text { known i }\end{array}$ & $\begin{array}{r}10 \\
1 \\
0 u r\end{array}$ \\
\hline
\end{tabular}

come of extradural haematoma. ${ }^{1}$ Only two neurosurgical units exist in the Irish Republic and with a poor road network, delay is inevitable. Eighty two cases had been audited.

Fifty two (63.4\%) cases exhibited a lucid interval and the table details the duration of transfer and the associated deterioration in level of consciousness of 46 patients.

Eight patients had no loss of consciousness, six had an initial loss of consciousness with a sustained recovery and 16 were never lucid. The outcomes included $66(80.5 \%)$ good; four $(4.9 \%)$ moderately disabled; two $(2 \cdot 4 \%)$ severely disabled; four $(4.9 \%)$ vegetative state and six $(7 \cdot 3 \%)$ dead.

The authors concluded that the delay in recognition and transfer was excessive which resulted in a high percentage of patients undergoing surgery in coma. Despite this, the results were favourable. ${ }^{2}$.

1 Mendelow AD, et al. Br Med J 1979;12:1240-2. 2 Lobato RD, et al. J Neurosurg 1988;68:48-57.

TRIPHENYLTETRAZOLIUM CHLORIDE (TTC) AS A MARKER OF ISCHAEMIC CHANGES IN RAT BRAIN AFTER MCA OCCLUSION

RH Hatfield. Cambridge. AD Mendelow, L Alvares. Newcastle.

Permanent middle cerebral artery occlusion (MCAO) in the rat is now widely used as a model of focal ischaemia for the assessment of neuroprotective agents. The usual end point involves volumetric analysis of the infarct with histopathology but this is expensive and time consuming. Using the mitochondrial redox stain TTC is cheaper and quicker, but it has limitations. The volume of ischaemic damage in rat cortex delineated by TTC was compared to the volume defined by histopathology at four hours and 24 hours after MCAO. Animals treated with the NMDA antagonist MK-801 (3 mg/kg ip 30 minutes post occlusion) were compared to controls. The volume of cortical damage expressed as $\mathrm{mm}^{3}$ (SEM) was:
In a further study a comparison was made of TTC staining by immersion or by perfusion techniques at 5-20 minutes, 3-4 hours and 24 hours after MCAO and in this case the lesion size was assessed by measuring the area of damage in single sections at the level of the anterior commissure. The results are expressed as $\mathrm{mm}^{2}$ (SEM):

$\mathrm{MK}-801$ is a good neuroprotective agent in this model. TTC is an excellent marker of ischaemic damage at $\mathbf{2 4}$ hours but is unreliable as a marker of tissue damage in acute studies.

COMPETITIVE NMDA ANTAGONISTS: A

VALUABLE TREATMENT FOR PREVENTING ISCHAEMIC NEURONAL DEATH?

R Bullock, J McCulloch, GM Teasdale, DI Graham, FM Inglis. Glasgow

Excessive release of excitatory neurotransmitter substances such as glutamate, aspartate, and acetylcholine damages neurones by causing prolonged depolarisation with massive influx of calcium and sodium ions, and efflux of potassium. This "excitoxic" mechanism has been shown to cause neuronal damage in models of epilepsy, ischaemia, and probably fluid percussion injury. Excitotoxicity is mediated largely via glutamatergic post-synaptic receptor sites, the most important of which (the NMDA sites) are amenable to pharmacological blockade.

Non competitive NMDA antagonist drugs (e.g. MK801) have been studied extensively in models of focal cerebral ischaemia, and have been shown to reduce infarct size dramatically (by $50 \%$ ), not only with pretreatment but more importantly by posttreatment up to two hours after occlusion. ${ }^{1}$ Unfortunately, non-competitive antagonists derange cerebral metabolism and function, particularly in limbic areas, and cause death in some animals, so that their clinical value is in doubt.

Recently a new competitive glutamatergic NMDA antagonist (S212-494) ${ }^{2}$ has been synthesised and we have studied its effects in the cat middle cerebral artery occlusion model.

\begin{tabular}{|c|c|c|c|}
\hline & Control & $M K-801$ & (Control vs MK-801) \\
\hline $\begin{array}{l}4 \text { hour ischaemia: Histology: } \\
\text { TTC: } \\
24 \text { hour ischaemia: Histology: } \\
\text { TTC: }\end{array}$ & $\begin{array}{ll}77 \cdot 2 & (6 \cdot 0) \\
91 \cdot 6 & (5 \cdot 1) \\
92 \cdot 8 & (6 \cdot 1) \\
95 \cdot 3 & (6 \cdot 0)\end{array}$ & $\begin{array}{ll}54 \cdot 4 & (6 \cdot 6) \\
81 \cdot 2 & (7 \cdot 7) \\
51 \cdot 9 & (9 \cdot 1) \\
51 \cdot 5 & (8 \cdot 1)\end{array}$ & $\begin{array}{l}\star(\mathrm{p}<0.05) \\
\quad(\mathrm{NS}) \\
\star \star(\mathrm{p}<0.002) \\
\star \star(\mathrm{p}<0.001)\end{array}$ \\
\hline
\end{tabular}

\begin{tabular}{|c|c|c|c|}
\hline Time & Perfusion & Immersion & $(P$ vs $I)$ \\
\hline $\begin{array}{l}24 \text { hours } \\
3-4 \text { hours } \\
5-20 \text { minutes }\end{array}$ & $\begin{array}{ll}17 \cdot 4 & (1 \cdot 3) \\
14.4 & (2 \cdot 3) \\
11.8 & (2 \cdot 3)\end{array}$ & $\begin{aligned} 17 \cdot 6 & (1 \cdot 6) \\
4 \cdot 4 & (2.5) \\
0.4 & (0.5)\end{aligned}$ & $\begin{array}{l}\text { (NS) } \\
(\mathrm{p}<0.05) \\
(\mathrm{p}<0.05)\end{array}$ \\
\hline
\end{tabular}


S212-494 was given 15 minutes prior to transorbital MCA occlusion in six anaesthetised cats. After six hours, perfusion fixation was performed. Infarct volume was quantitatively measured by mapping the area of infarction in serial brain sections and taken at 16 stereotactic planes and compared to infarcts in six control animals.

S212-494 achieved a $65 \%$ reduction in total infarct size $(76 \%$ reduction in cortex) when compared to controls. This magnitude of protection is slightly greater than that achieved in this model with non-competitive antagonists, and double that achieved by Nimodopine. S212-494 is a potent anti-ischaemic agent. Competitive NMDA antagonists may have less detrimental effects on the limbic system than non-competitive agents and therefore provide a powerful, clinically useful treatment for acute cerebral ischaemia.

1 Park CK, et al. J CBF Metabol 1988;8:757-62.

2 Aebischer B, et al. Helvetia Chimica Acta 1989; 72:1-9.

THE EFFECT OF HYPONATRAEMIA ON THE VASOMOTOR RESPONSES OF THE CEREBRAL CIRCULATION BEFORE AND AFTER

EXPERIMENTAL SUBARACHNOID HAEMORRHAGE RJ Nelson, S Perry, ACR Burns, J Roberts, JD Pickard. Southampton

Hyponatraemia is a frequent complication of intracranial disease and can in itself be responsible for neurological deterioration. It is associated with an increased incidence of cerebral infarction following subarachnoid haemorrhage (SAH). ${ }^{1}$ Impairment of cerebrovascular reactivity and cerebral autoregulation play an important role in the development of delayed cerebral ischaemia after SAH. However, very little is known of the effects of hyponatraemia on the vasomotor responses of the cerebral circulation either before or after SAH.

We have studied cerebrovascular reactivity to hypercapnia and cerebral autoregulation to trimetaphan-induced hypotension in normal and hyponatraemic rabbits of both sexes before and six days after SAH. SAH animals received two intracisternal injections of 0.5 $\mathrm{mls} / \mathrm{kg}$ of autologous blood on days 0 and 2 . Hyponatraemia (mean plasma [Na] 119 $\mathrm{mmols} / \mathrm{l}$ ) was induced over 48 hours by $\mathrm{s} / \mathrm{c}$ injection of DDAVP and intraperitoneal infusion of $5 \%$ dextrose on days 4 and 5 . Sham animals received normal saline.

The cerebrovascular reactivity (\% change in cortical CBF measured by hydrogen clearance $/ \mathrm{mm} \mathrm{Hg}$ increase in $\left.\mathrm{PaCO}_{2}\right)$ of hyponatraemic $(4.8 \pm 1.4)$ and SAH $(1.3 \pm$ $0.8)$ animals was significantly less $(p<0.05$, by analysis of variance) than control (11.6 \pm $2 \cdot 1)$ and sham $(8 \pm 1 \cdot 1)$ animals. The reactivity of hyponatraemic-SAH animals was preserved $(9 \cdot 2+2 \cdot 7)$.

During trimetaphan-induced hypotension the mean CBF of control and sham animals did not change significantly until MABP had fallen to 30 and $40 \mathrm{~mm} \mathrm{Hg}$ respectively. The cerebral autoregulation of the hyponatraemic, SAH and hyponatraemic-SAH animals, was significantly impaired. The pathophysiological consequences of these findings were discussed.

1 Wijdicks EFM, Vermeulen M, Hijdra A, van Gijn J. Ann Neurol 1985;17:137-40.

This work was supported by the Wellcome Trust.
VASOCONSTRICTOR RESPONSES TO ENDOTHELIN IN CAT PIAL VESSELS IN SITU

MJ Robinson, TL Grant, J McCulloch. Glasgow

Endothelin is a 21 amino acid peptide first demonstrated to be released from cultured aortic endothelial cells by Yanagisawa $e t$ al. Endothelin has previously been shown to have potent and prolonged vasoconstrictor activity in extracranial vessels. The authors used a cat pial window preparation ${ }^{2}$ to apply endothelin $\left(3 \times 10^{-10} \mathrm{M}\right.$ to $\left.3 \times 10^{-6} \mathrm{M}\right)$ directly to individual pial arterioles and veins and demonstrated strong dose-dependent vasoconstrictor responses in both pial arterioles $(\max -33.5 \% \pm 3.8 \% ; n=6-9$ ) and pial veins $(\max 35 \cdot 1 \% \pm 2.7 \% ; n=6-9)$. On a molar basis endothelin is among the most potent vasoconstrictor agents yet described. Arterioles remain significantly constricted ( $p<0.05 ; n=5-9$ ) compared to controls for 90 minutes following a single microapplication of endothelin. This is far in excess of the duration of constriction seen with any other agent in this preparation.

Nevertheless, exposure of arterioles preconstricted by endothelin $\left(3 \times 10^{-8} \mathrm{M}\right)$ to $\mathrm{K}^{+}$ $10 \mathrm{mM}$ in CSF and alkalotic CSF $\left(\mathrm{HCO}_{3}-22\right.$ $\mathrm{mM}$ ) resulted in rapid vasodilation $(+63.0 \%$ $\pm 11.8 \%)$ and vasoconstriction $(-22.7 \% \pm$ $6 \cdot 1 \%$ ) respectively followed by return to their endothelin constricted calibre.

The authors considered it paradoxical that such potent and prolonged cerebral vasoconstriction, to levels consistent with impairing local cerebral blood flow, is nevertheless still so responsive to changes in the local ionic environment, putatively the endogenous mechanism of cerebral microvascular regulation.

1 Yanagisawa $M$, et al. Nature 1988;332:411-5. 2 Edvinsson L, et al. Acta Physiol Scand 1984;122: $155-63$.

ISCHAEMIC MENTAL DETERIORATION REVERSIBLE AFTER CEREBRAL REVASCULARISATION: CORRELATION OF SINGLE-PHOTON HEMODYNAMIC ASSESSMENT WITH NEUROPSYCHOLOGICAL STUDY IN FIVE PATIENTS

JM Derlon, F Viader, MB Desgrange, G Bouvard, MC Petit, $M$ Thomas-Lamotte, JP Houtteville, M Dress, B Dupuy. Caen, France

Five patients were referred for multiple obstructive lesions of the supraaortic arteries, and progressive mental impairment over the six months before admission. Only one patient had a fixed (and moderate) focal deficit, two patients presented with TIA's, and the last two had no focal neurological event at all. In all patients, the neuropsychological evaluation indicated an impairment of mental function involving both verbal and non-verbal abilities and a dysfunction of both cerebral hemispheres. The CT scan was within the normal range or disclosed only small hypodense ischaemic areas which could not explain the mental disorders. Hemodynamic assessment included a rCBF study with external counting (Novo-Cerebrograph (R)) of the inhaled 133Xe before and after IV acetazolamide, and a SPECT measurement of the rCBV (after transfusion of autologous $99 \mathrm{~m} \mathrm{Tc}$-labelled erythrocytes). In all five patients a severe haemodynamic reserve impairment was found, with low resting rCBF which did not significantly increase on either side after IV acetazolamide. A revascularisation procedure was performed in all patients (ECIC by-pass in three, ICA endarterectomy in two). In all five patients there was very obvious improvement of both the hemodynamic parameters (resting $\mathrm{rCBF}$ and response to IV acetazolamide) and neurological tests. Hence, some cases of ischaemic mental deterioration may be the consequence of chronic cerebral hypoperfusion and might benefit from surgery. The criteria used to identify such patients were: mental impairment of recent onset (less than six months) with or without a minor or improving focal neurological deficit; a CT scan that is normal or shows only minor changes; multiple carotid or vertebral obstructive lesions on angiography; symmetrical rCBV and severely reduced $\mathrm{rCBF}$ with no increase in $\mathrm{rCBF}$ following IV acetazolamide.

RADIOLOGICAL ASSESSMENT OF ASYMMETRY IN THE VERTEBRO-BASILAR CIRCULATION IN RELATION TO THE AETIOLOGY OF TRIGEMINAL NEURALGIA

R Illingworth, P Richards, R Sil. Charing Cross, London

Does asymmetry in the configuration of the superior cerebellar artery (SCA) explain the right-sided and female predominance in trigeminal neuralgia?

Vertebral angiograms in 376 patients, 206 females and 170 males, were measured in the lateral, and AP or Townes projections in relation to the skull. Loops were assessed for depth and asymmetry, and in relation to sex, age and arterial hypertension. The angiograms had been performed for SAH in $82 \cdot 7^{\circ}$; studies for hydrocephalus, mass lesions, vertebro-basilar aneurysms and trigeminal neuralgia were excluded.

1 Depth of SCA loops: overall the mean depth was $12.07 \mathrm{~mm}$ in males and $11.36 \mathrm{~mm}$ in females (ns). The left SCA looped lower in the AP view in males than in females $(P=0.033)$.

2 Asymmetry: the SCA looped lower more often on the right side in females aged 50 to 80 $(P=0.04)$. Asymmetry in the curve of the basilar artery and in the dominance of the vertebral arteries was commoner in women $(P=0.01)$. Deepest SCA loops were the most asymmetrical $(P=0.0001)$.

3 Age: in the whole group and in females depth of the SCA loop increased with age. $(\mathrm{P}=0.0001)$.

4 Hypertension: the depth of the SCA loops in males and females increased with hypertension. $(P=0.005)$.

In conclusion, tortuosity in the vertebrobasilar system increases with age and hypertension but the SCA does not loop lower in females than in males. Asymmetry in the vertebro-basilar arteries is commoner in females and in older women the right SCA loops lower more often than the left.

REVERSE TENTORIAL HERNIATION:

"UPCONING"

NV Todd, DM Hadley, D Doyle, JD Miller. Glasgow

The authors review 11 cases of postmortemconfirmed "Upconing" extracted from the neuro-pathology records from 1967-1988. Upconing was defined as upward displacement of the vermis with brainstem compression. It presented clinically with abrupt coma 
(4), failure to recover from operation (4) or progressive deterioration (3). Pupils were dilated in seven, small and fixed in one and normal in three patients. Primary pathology was tumour (4), haematoma (5), infarct (1) and abscess (1) associated with brainstem shift (10), brainstem haemorrhage or infarct (5), tonsillar herniation (6) or posterior circulation infarct (4). CT or MR scanning confirmed "Upconing" in all cases. Primary management had been ventricular drainage (6) or posterior fossa decompression (2) with subsequent drain occlusion (1) or posterior fossa decompression (3).

A cause for the abrupt pressure change across the tentorium could be identified in all patients ( 15 events in 11 patients): posterior fossa haemorrhage (8), ventricular drainage (5), tumour or infarct swelling (2).

The authors concluded that "Upconing" was uncommon and may be associated with any posterior fossa lesion. They found no clinical features that predicted subsequent "Upconing" and, contrary to other reports, no specific clinical profile of "Upconing". Diagnosis should be suspected in patients who abruptly deteriorate or who fail to recover from the primary operation. CT or MR scanning will confirm diagnosis and management requires rapid reversal of the transtentorial pressure gradient by shunt occlusion with or without posterior fossa decompression.

POST-TRAUMATIC CEREBELLAR SYNDROME: A CLINICO-PATHOLOGICAL STUDY. DOWNS TRAVELLING SCHOLARSHIP 1988 PV Marks. Cambridge

The post-traumatic cerebellar syndrome (PTCS) is not uncommon, yet its pathological substrate is ill-defined with either direct cerebellar damage or brainstem damage being implicated. In view of this uncertainty, a study of 20 patients who exhibited fixed PTCS was conducted.

All neuropathological abnormalities were recorded together with a quantitative study of the Purkinje cell population, the neuronal population of the dentate nucleus and the inferior olivary nucleus to determine whether there was a reduction in the Purkinje cells and neurones in closely related structures.

Supratentorial damage in the form of old contusions was observed in every case and the mean total contusion index for the series was 3.7. The classical stigmata of diffuse axonal injury or of raised intracranial pressure were not seen in any of the cases.

A mean reduction of the Purkinje cell population of $40 \%$ was found associated with a concomitant reduction of the neuronal population of the dentate nucleus. No abnormalities were observed in the thalamus, red nuclei or inferior olivary nuclei, but demyelination was seen in the superior cerebellar peduncles of 11 cases and in the pyramidal tracts of five cases. Evidence of cerebellar scarring was seen in eight cases and this was localised either to the tonsillar region or the antero-lateral aspects of the hemispheres.

The mechanism and underlying pathological disturbances resulting in PTCS are undoubtedly complex: it is proposed that they result from a combination of direct cerebellar injury and of shearing which produces damage to the brainstem connections of the cerebellum.
FIBRIN GLUE FACIAL NERVE GRAFTING AT THE TIME OF ACOUSTIC NEUROMA SURGERY

AR Walsh, S Falci, NF Weir, M Schwartz, BA Bell, D Uttley. Atkinson Morley's Hospital, London

Permanent loss of facial nerve function is a significant cause of morbidity following successful surgery to remove a large acoustic neuroma. None of the existing techniques to ameliorate the facial palsy are entirely satisfactory.

The authors presented their results of immediate grafting of the divided facial nerve with a portion of sural nerve using fibrin glue (Tisseel) to secure the anastomoses. Of 26 patients operated on in the past two years, the facial nerve was left anatomically intact in 13 $(50 \%)$. In two the facial nerve was divided and anastomosed end to end with Tisseel, and in 11 a sural graft was anastomosed between the cut ends with Tisseel.

Follow up comprised regular clinical assessment and facial EMG's. One patient with a sural graft died two weeks postoperatively, leaving 10 patients with follow up of three to 18 months (mean 10 months). Earliest recovery occurred at nine months with partial restoration of resting tone and eye closure. Voluntary facial movement recovered between 12 and 18 months. Three of the four patients whose follow up exceeded 12 months had voluntary facial movement, and five of six patients followed for nine months or more had recovered facial tone.

The authors found this technique simple to perform at the end of the operative removal of an acoustic neuroma, and the recovery of facial nerve function at 12 months was encouraging.

NEUROSURGICAL CONTRIBUTION TO DISASTER MANAGEMENT: A PRACTICAL STUDY

BD White, CJ Mumford, JM Rowles, JL Firth. Nottingham

On 8 January 1989, a Boeing 737 aircraft with 126 people aboard crashed on approach to the East Midlands Airport with the immediate loss of 39 lives and many severe injuries. The authors had determined the mechanism of injury in each case of head injury. There were seven severe head injuries of whom three died. Six were hit from behind-three deaths were associated with diffuse brain swelling; in the survivors there was one sub-dural and one extra-dural haematoma. The non severe head injuries were all examined and interviewed to obtain the pattern of head and facial bruising, the extent of traumatic amnesia, the duration of loss of consciousness, the location within the aircraft and whether the braced position had been adopted.

Factors that emerged included crushing by the disintegrating airframe, failure of restraint, relative in ability to escape from the aircraft, and of considerable relevance to the head injuries, the risk of being hit on the head and neck from behind by an unrestrained flying object particularly if the brace position was not adopted.

DO BRADYKININ AND ARACHIDONIC ACID CONTRIBUTE TO THE PATHOPHYSIOLOGY OF PERITUMOURAL BRAIN OEDEMA? IR Whittle, JD Miller. Edinburgh

Peritumoural brain oedema arises mainly from neoplastic endothelium. It has been proposed that "secondary mediators" released by tumours contribute to the pathophysiology of this oedema ${ }^{1}$ and that steroids inhibit these adverse effects. To investigate the possible roles of bradykinin and arachidonic acid the infusion model of brain oedema ${ }^{2}$ was used.

Bradykinin (5 and $150 \mu \mathrm{g} / \mathrm{ml}$ ) and arachidonic acid $(2-15 \mathrm{mg} / \mathrm{ml})$ were slowly infused into the right forebrain white matter of the cat $(n=15)$ and multiple neurophysiological parameters monitored. Both infusates caused focal brain oedema (mean $11 \mathrm{~g} \mathrm{H}_{2} \mathrm{O} / 100 \mathrm{~g}$ tissue), focal disruption of the BBB to Evans Blue, perivascular leucocytic infiltrates, moderate rises in ICP (mean $12 \mathrm{~mm} \mathrm{Hg}$ ), and a fall (mean $70 \%$ ) in lumped craniospinal compliance. There was no alteration at normocapnia in regional $\mathrm{CBF}$ or change in somatosensory or motor evoked potentials.

These results confirm that bradykinin and arachidonic acid can potentiate peritumoural brain oedema formation and are chemotaxic for neutrophils. However, in view of the lack of vasomodulation or electrophysiological changes it is unlikely that they contribute significantly to the pathophysiology of peritumoural brain dysfunction. The disparities between these and previous in vitro findings on the vaso- and neuromodulative effects of bradykinin and eicosanoids were discussed. 1 Wahl M, Unterberg A, Baethmann A. J CBF

2 Marmarou A, Takagia H, Shulman K. $A d v$ Neurol 1980;28:345-58.

INFLUENCE OF HYPOXIA ON FLOW AND PERFUSION THRESHOLDS FOR SOMATOSENSORY EVOKED POTENTIALS

P Eldridge, DT Hope, PM Yeoman, I Farquhar, M Mitchell, S Clarke, NJ Smith. Nottingham

Somatosensory evoked potentials (SSEP) depend for their integrity on a minimum cerebral blood flow (CBF) and therefore a minimum cerebral perfusion pressure (CPP) together with adequate oxygenation. Since the $\mathrm{CBF}$ required to maintain cellular integrity is close to that required to maintain electrical function, the behaviour of somatosensory evoked potentials in an experimental situation should predict the clinical situations in which the brain would be at greatest risk.

A model of intracranial hypertension was made in the cat by infusing saline into the lumbar sac. A uniform rise in intracranial pressure was obtained, and the pressure increased until SSEP were lost. CBF was measured by hydrogen clearance and CPP recorded. SSEP were abolished at CPP of 13 $\mathrm{mm} \mathrm{Hg}$ and a CBF of $10 \mathrm{ml} / 100 \mathrm{~g} / \mathrm{min}$ in a normally oxygenated animal.

A second group of animals were made mildly hypoxic: p02 of $9 \mathrm{kPa}$. In this group SSEP were abolised at CPP of $20 \mathrm{~mm} \mathrm{Hg}$ and a CBF of $15 \mathrm{ml} / 100 \mathrm{~g} / \mathrm{min}$. The difference between the groups is significant $p<0.05$. The quantitative difference is consistent with that predicted from the difference in oxygen carriage in the blood between groups.

Hence thresholds were significantly elevated with mild hypoxia. Although SSEP was lost at too low a value of CPP or CBF to be directly useful in clinical monitoring, these thresholds were raised such that even mild degrees of hypoxia are clinically relevant. 
THE ELECTROMOTIVE POTENTIALS OF ANEURYSM CLIPS

PV Marks, MH Christie, RH Hatfield, A Waters. Cambridge

The production of electrical currents by the immersion of metals in electrolyte solutions, as well as their effects upon living tissue, has been known since the time of Volta and Galvani.

Dental surgeons have known for many years that if metallic prosthetic or restorative materials of dissimilar composition are used, electrical currents are generated within the buccal cavity.

These various observations prompted the Authors to study the electromotive potentials of aneurysm clips in vitro and in vivo so as to establish the magnitude of the potential produced, the factors influencing such potentials and the possible effects on vascular smooth muscle.

It was found that an instantaneous voltage as high as $\mathbf{2 5 0}$ millivolts was produced on application of the clips to the rat common carotid artery and this decreased to between 50 and 80 millivolts after 120 seconds. With some clips, potentials of this order were maintained for four hours or longer.

As such voltages are of physiological magnitude, their effect on the resting potential of vascular smooth muscle was examined and found to be significant.

As the aetiology of post-operative vasospasm is undoubtedly multifactorial, any reduction in potential contributory factors is likely to be beneficial. Hence the authors proposed that clips which produce the smallest EMF should be chosen, and where possible multiple clips should be avoided. If this is not possible, the clips should be of similar type and composition. A lively discussion ensued.

NEUROSURGICAL AUDIT

The Round Table Discussion included three short papers and a wide ranging examination of the principles and mechanisms of audit.

The problems of information technology and outcome assessment were addressed in the short papers but consideration also had to be given to agreement for peer review, the setting of standards for each indicator and comparison of current practice with such standards. The cycle of audit would only be completed when change was implemented as required and the effect of such changes defined by remeasurement. Such audit was labour intensive and audit assistants would have to be provided. Problems of confidentiality were discussed and it became clear that all records are becoming part of the discovery process by solicitors and that there is no time limitation on such a discovery. Supraregional comparisons were required. Contracts to provide a service must define in detail the spectrum of severity of the cases to be treated together with the quality of care and costs of confirming such quality including postmortem examination. Such mechanisms should not be restricted to the National Health Service but must include any health care system bidding for such contracts.

1 EXPERIENCE WITH THE ICS NEUROSURGICAL AUDIT SYSTEM

G Brocklehurst. Hull

The tradition of good documentation has been maintained in neurosurgery in order to facilitate both continuity of patient care, and research. The Neurosurgical Audit System developed by Intelligent Computer Services was installed by the beginning of 1989 .

Alterations in computer capacity and processing were required to achieve efficient performance of the system. The Patients Entry Form provided by the software proved more than adequate for administrative and clinical purposes, but the Audit Entry Form required alteration of some fields and extensive editing of the attached file for diagnostic coding before it was clinically useful.

The Reports already incorporated in the system were more suited to research for administrative purposes such as audit and resource management than for academic use. A further Report Form had to be constructed to provide a printed Inpatient Summary needed for continuity of patient care. It was necessary for Clinicians to sit alongside the secretary for the production of such summaries.

The ICS Neurosurgical Audit System can be used to provide good neurosurgical documentation but could be improved further. Outpatients were not yet included in the system.

\section{EVALUATION OF A ONE YEAR MORTALITY} AND MORBIDITY NEUROSURGICAL UNIT AUDIT R Garlick, RS Maurice-Williams, N Olsen. Royal Free, London

The authors reported the outcome of the first year of an audit system as applied to surgical operations carried out in a regional neurosurgical unit.

Six hundred and forty six operations were performed from 1 July 1988 to 31 June 1989. The operating surgeon completed a questionnaire containing 21 items of information and this was ratified by a weekly meeting of an audit committee. Data relating to the following was obtained: patient age, diagnosis, intercurrent illness, type of operation, surgeon involved, operative problems (13.1\%), post-operative complications (surgical site $(18 \cdot 1 \%)$, other $(8.5 \%)$ ), outcome and number of days from operation to discharge. The association between the occurrence of operative problems and complications at the surgical site did not achieve statistical significance $(p=0.06)$. The authors emphasised that one individual should be responsible for organisation of such meetings with collation of the information and that the weekly reviews must be formalised. Precise definitions and coding were required though the difficulties of ascribing complications to the disease itself or defects in surgical technique were highlighted. The educational value of audit was stressed.

3 KEEPING THE SCORE: NEUROSURGICAI AUDIT OF CLINICAL OUTCOME CHA Meyer, ER Hitchcock. Birmingham

A method was presented for describing the clinical outcome of management suitable for the audit of a wide range of conditions met in neurosurgical practice. Clinical outcome was described by a profile of ratings including changes in disability (the Karnovsky scale), change in presenting symptoms, operative effect on the underlying pathological progress, and clinical deterioration. Based on a 10 year experience with this aspect of clinical audit the method was illustrated by reference to groups of patients treated for ruptured cerebral aneurysms, brain glioma, trigeminal neuralgia and carpal tunnel syndrome.

The data for such audit was quick and easy to obtain and record-facilitating electronic storage, retrieval and analysis

The Rowbotham Memorial Lecture was delivered by Professor DP Becker, UCLA

School of Medicine, United States, on The Scientific Basis for the Management of Brain Trauma. 